\title{
Analysis on Behavior Factors of Successful Entrepreneurship of College Students of Local University in Guangdong Province
}

\author{
Li Bing-quan ${ }^{1}$, Hu Rong ${ }^{2}$, Du Hai-xin ${ }^{3}$, Zhang Xu-dong ${ }^{4}$ \\ ${ }^{1}$ The professor and doctor of psychology, the Vice-dean of Educational Science School, Zhaoqing \\ Univerisity. Honorary Chairman, Guangdong, Xinzhou Sixth Ch'an Patriarch Huineng Culture \\ Research Institute, Guangdong, China \\ ${ }^{2}$ Educational Science School, Zhaoqing Univerisity \\ ${ }^{3}$ Educational Science School, Henan University, China \\ ${ }^{4}$ The professor and doctor of psychology, the dean of Educational Science School, Zhaoging \\ University, China \\ Email: libq1221@163.com
}

\begin{abstract}
:
Research purpose: To understand the behavioral factors affecting the success of college students' Entrepreneurship. Research tools: the College Students' Daily Success Behavior Scale (CSDSB) and the College Students' Entrepreneurship Scale (CSES). Research methods: Psychometric method and Interview method. Research objects or samples: 32 college students in Guangdong Province who are starting their own businesses. Results: (1) The total score of college students' daily success behavior and its five dimensions are positively correlated with the total score of college students' entrepreneurship and its four dimensions. (2) The total score of college students' daily success behavior and the dimension of "Excelsior (Ex)" have significant positive predictive effects on their entrepreneurial ability ( $F=32.375, P<0.001)$. (3) Successful entrepreneurs possess behavioral quality consistent with the dimensions of the college students' daily behavior scale. Conclusion: Daily behavioral factors have a significant positive predictive effect on college students' entrepreneurship.

Keywords:

college students; success daily behavior; latent class analysis; entrepreneurship; success; local university
\end{abstract}

\section{Introduction}

Facing the complicated new era, the daily behavior problems of college students are becoming more and more prominent. The daily behavior problem of college students means the daily behaviors that are not conducive to students' physical and mental health development, campus life and learning life, and social development. Lao Tzu, the founder of Taoism in China, once said: "difficult things in the world must be done in the easy, and great things in the world must be done in detail." Which tells us, if we want to do a great thing well, we must first do it in detail. Ouyang Xiu, a writer in the Northern Song Dynasty, also said: "disasters often accumulate in twinkling", which meaning is that some trivial things may also lead to great disasters. Zhang Ruimin, president of Haier, once said: "it is not easy to do every simple thing well, it is unusual to do every ordinary thing well." These words all tell us the importance of people's daily behavior to their development. For college students, perfecting individual moral behavior is beneficial to the consolidation and development of their cognitive, emotional and volitional qualities. An important factor for the improvement of college students' undefined comprehensive quality is to have good moral literacy, which is also one of the capital that they will be recognized after their stepping into society(Liu, 2017). In daily life, there are some behaviors that are difficult to be conscious, not easy to be noticed, and easy to be overlooked, but in fact, they are of great significance to the success of college 
students. It can be seen that daily behavior of college students plays an important role in their success.

In today's post-industrial society, the innovation and entrepreneurship has become an important driving force for economic development and structural transformation (Rosmadi, 2018), especially for China. Therefore, innovation and entrepreneurship have been being attached great importance as an important way of social development and the great rejuvenation of the Chinese nation. It is in this social context that the call of "mass entrepreneurship, mass innovation" has been put forward to call on people to actively participate in the social practice of innovation and entrepreneurship in China. Such a society, on the one hand, puts forward the requirement, but also provides favorable social conditions and positive atmosphere for the innovation and entrepreneurship of college students. But it is not so easy to innovate and start a business. Mr. Gartner believes that entrepreneurship includes both the outcomes of entrepreneurial behavior and personal characteristics of the entrepreneur. The outcomes of the entrepreneurial behavior include the acquisition of the maximum profit, the creation of the individual and the social value, the management and the owner of an enterprise, and the construction of the organization; the individual characteristics of the entrepreneurs include entrepreneurial personality, uniqueness, innovation, exploiting of new enterprise and development sought (Gartner, 1990). As a key group cultivated by society, college students are closely related to the development of the nation (Amal, Natsir, Supsiloani, Suswati, 2019). By cultivating entrepreneurial quality of college students, a large number of highquality entrepreneurial talents would be delivered to the society, the social contradictions of the college students employment difficulties would be effectively relieved, and the development of the entrepreneurship-type economy and the construction of the innovative country would be promoted (Rosmadi, 2018). In addition, the reform of higher education would be further deepen, and the personnel training mode would be innovated (Gu, 2013).

As President $\mathrm{Xi}$ Jin-ping said in his address to the 19th national congress of the communist party of China (CPC), "A country will thrive when its young people thrive, and a country will become strong when its young people are strong. If the younger generation has ideals, abilities and responsibilities, the country would have a future and the nationality would have hoped." From the perspective of college students' innovative consciousness, although there are some innovative talents among college students, the overall situation of college students shows that their innovative consciousness and ability are not enough to cope with the challenges of today's era. In the context of the great improvement of the comprehensive national strength of many countries in the world, innovation provides an inexhaustible driving force for the development of a country and a nation. Therefore, it is increasingly urgent to cultivate a large number of innovative talents (Wang, 2019). In the past, the research about daily behavior mainly focus on the cultivation and training of people's daily behavior. The research on entrepreneurial ability of domestic and foreign scholars is given priority to the cultivation of entrepreneurship. Although there have achieved fruitful results in the research in daily behavior and entrepreneurship, there is very little research on the impact of daily behavior on college students who are starting a business. Since the college students who are starting their own businesses have richer and deeper understanding and experience of entrepreneurship than ordinary college students, the investigation of these students are helpful to more accurately understand the relationship between behavioral factors and entrepreneurship. For this reason, this research studies the daily behaviors that affect the successful entrepreneurship of college students, so as to provide more targeted suggestions for them to constantly adapt to the competition of society and cultivate their success qualities in order to make them have proper learning behaviors, daily life behaviors, communication behaviors and other that are able to 
adapt to and promote the development of the times (Li, 2010).

\section{Research Methods}

\subsection{Objects}

\section{a. Questionnaire Subjects}

A total of 35 questionnaires were randomly sent out to college students in 14 local colleges and universities, including Zhaoqing University, Zhongkai Agricultural University, DongSoft College, Guangdong Technical Normal College, Huizhou University, Lingnan Normal University and Foshan Vocational and Technical College. 35 questionnaires were eventually collected with a recovery rate of $100 \%$. 3 invalid questionnaires were excluded, 32 valid questionnaires were obtained, the effective rate was $94.29 \%$. Among them, there are 1 freshman, 1 sophomore, 14 junior and 16 senior students; 12 boys and 20 girls; 9 science students, 20 liberal arts students and 3 technical students; 6 only-child students and 26 nononly-child students; 15 urban students and 17 rural students; 7 normal students and 25 nonnormal students.

\section{b. Interviewees}

In order to deeply understand the daily behavioral quality and successful experience of entrepreneurs, and the relationship between daily behavioral factors and successful entrepreneurs, four students who are successful entrepreneurs from Shaoguan University, Zhaoqing University and Panyu Vocational and Technical College of Guangdong Province were interviewed by random sampling.

\subsection{Research Tools}

\section{a. College Students' Daily Success Behavior Scale (CSDSBS)}

The college students' daily success behaviors (CSDSB) were measured by college students' daily success behavior scale (CSDSBS) compiled by Li Bing-quan, Zhang Ying, Shang Zhuo-rui, Hu Rong, Yang Rui-na and Li Jin-lian. The scale has a total of 36 items, including 6 factors, which are Dream (D), Physical and Mental Health (PMH), Excelsior (Ex), Self-uniqueness (Su), Creativity (C) and Integrity (I). The reliability coefficients of each dimension of the scale ranged from 0.655 to 0.864 , and the validity ranged from 0.429 to 0.769, with good reliability and validity (Zhang, Shang, Hu, etc., 2019).

\section{b. College Students' Entrepreneurship Scale (CSES)}

College students' entrepreneurship (CSE) was measured by the College Students' Entrepreneurship Scale (CSES) revised by Wang Yu-min, which is based on the Entrepreneurship Scale compiled by $\mathrm{Xu} \mathrm{Yi}$ in her master's thesis Compilation of Entrepreneurship Scale. The scale has a total of 27 items, including 4 factors, which are entrepreneurial intention (EI), interpersonal communication ability (ICA), leadership ability (LA) and innovation ability (IA). The reliability and validity of the scale are high. The homogeneous reliability coefficient is 0.92 , and the internal consistency reliability of each subscale ranges from 0.65 to 0.78 . The questionnaire adopts a five-point scoring method, with 1 indicating "nonconformity" and 5 indicating "conformity" (Wang, 2014).

\subsection{Methods}

\section{a. Interview Method}

An interview questionnaire that is suitable for college graduates is compiled on the basis of the interview design in Huang Ziwei's thesis "On cultivating innovation and entrepreneurship talents for foreign language majors from the perspective of entrepreneurship experience interview"(Huang, 2018). The questionnaire includes 8 questions of the interview 
on the definition and understanding of entrepreneurship, entrepreneurship opportunities, entrepreneurship behavior quality and entrepreneurship quality training, which are as follows:

1. How do you understand entrepreneurship?

2. When did you start to have entrepreneur idea? What prompted you to have this idea?

3. When did you start your business? What was the reason that you chose to start your business?

4. If you use a few keywords to summarize the process of entrepreneurship, which words would you choose?

5. What do you pay most attention to during your entrepreneurship?

6. What do you think are your most valuable qualities in the process of starting a business?

7. What qualities do you think college students should possess in starting a business?

8. Do you think innovation and entrepreneurship training is important for college students? How to cultivate them?

\section{b. Psychometric method and Questionnaire method}

CSDSBS is used to measure the daily success behaviors of research objects, and CSES to measure the entrepreneurship of research objects.

\subsection{Statistical tools and data analysis methods}

SPSS21.0 was used to analyze and process the data. SPSS21.0 was used to input the data, to convert the data of the College Students' Daily Success Behavior Scale into 0 and 1 scores, and to analyze the differences of demographic variables distribution and entrepreneurship intention of every latent class.

\section{Discussion}

\subsection{Results}

\section{a. The overall situation of college students' daily success behavior}

In general, descriptive statistics are used to describe college students' daily success behavior, including the total average score and all dimensions of college students' daily success behavior. The results are shown in Table 1. According to the total average score of each dimension, six dimensions can be ranked: Dream(D), Excelsior(Ex), Integrity(I), Physical and Mental Health(PMH), Self-uniqueness(Su) and Creativity $(\mathrm{C})$; among them, D dimension has the highest score (mean $=4.08)$, creativity dimension has the lowest score $(\overline{\mathrm{x}}=3.49)$, and college students' daily successful behavior is always worth it. It was divided into $3.84+0.52$.

Table 1. The results of descriptive statistics about CSDSB $(\mathrm{N}=32)$

\begin{tabular}{cccccc}
\hline & $\mathrm{N}$ & minimum & maximum & $\mathrm{S}$ & $\overline{\mathrm{x}}$ \\
\hline $\mathrm{D}$ & 32 & 2.33 & 5.00 & 0.6 & 4.08 \\
$\mathrm{I}$ & 32 & 1.88 & 5.00 & 0.77 & 3.94 \\
$\mathrm{C}$ & 32 & 1.50 & 5.00 & 0.80 & 3.49 \\
$\mathrm{PMH}$ & 32 & 2.80 & 5.00 & 0.60 & 3.83 \\
$\mathrm{Ex}$ & 32 & 2.25 & 5.00 & 0.67 & 3.98 \\
$\mathrm{Su}$ & 32 & 1.75 & 5.00 & 0.78 & 3.75 \\
$\mathrm{CSDSB}$ & 32 & 2.41 & 5.00 & 0.52 & 3.84 \\
\hline
\end{tabular}

Noting is "Dream", "I" is "Integrity", "C" is "Creativity", "PMH" is "Physical and mental health", "Ex" is "Excelsior", "Su" is "Self-uniqueness", "CSDSB" is "collage students' daily success behavior". Similarly hereinafter. 


\section{1) Differences in variables of CSDSB}

The independent sample T test was used to test whether CSDSB had the difference in only-child, major and gender. the results (seeing Table 2, the factors without significant difference were not included in the table, similarly hereinafter) showed that there were significant gender differences in the dimension of creativity, male students were significantly higher than girls, which indicates that male creativity was stronger, but there was no significant difference in major and only-child.

Table 2. Comparison of differences of CSDSB in only-child or non, Major, Gender $\mathrm{M} \pm \mathrm{SD})$

\begin{tabular}{cccc}
\hline & Male $(\mathrm{n}=12)$ & Female $(\mathrm{n}=20)$ & $\mathrm{t}$ \\
\hline $\mathrm{C}$ & $3.99 \pm 0.72$ & $3.20 \pm 0.72$ & 3.00 \\
\hline Noting: & $*$ is " $\mathrm{p}<0.05$ ”, $* *$ is “ $\mathrm{p}<0.01$ ”, $* * *$ is " $\mathrm{p}<0.001$ ”. Similarly hereinafter.
\end{tabular}

\section{2) The analysis of correlation between CSDSB and CSE}

It is shown in Table 3 that the total average score of CSDSB and its five dimensions with the exception of $\mathrm{Su}$ are positively correlated with the total score of CSE and its four dimensions at 0.05 level (bilateral) and that the correlation coefficient between CSDSB and the total average score of CSE is 0.794, which indicates that CSDSB is positively correlated with CSE.

Table 3. The analysis of correlation between CSDSB and CSE and its 5 dimensions

\begin{tabular}{cccccc}
\hline & EI & ICA & LA & IA & CSE \\
\hline D & $0.554^{* *}$ & $0.447^{*}$ & $0.669^{* *}$ & $0.655^{* *}$ & $0.673^{* *}$ \\
PMH & $0.445^{*}$ & $0.560^{* *}$ & $0.510^{* *}$ & $0.355^{*}$ & $0.545^{* *}$ \\
Ex & $0.664^{* *}$ & $0.632^{* *}$ & $0.779^{* *}$ & $0.657^{* *}$ & $0.794^{* *}$ \\
C & $0.653^{* *}$ & $0.599^{* *}$ & $0.598^{* *}$ & $0.491^{* *}$ & $0.683^{* *}$ \\
I & $0.513^{* *}$ & $0.405^{*}$ & $0.497^{* *}$ & $0.507^{* *}$ & $0.560^{* *}$ \\
CSDSB & $0.680^{* *}$ & $0.632^{* *}$ & $0.756^{* *}$ & $0.663^{* *}$ & $0.794^{* *}$ \\
\hline
\end{tabular}

Noting: "EI" is "entrepreneurial intention", "ICA" is "interpersonal communication ability", "LA" is "leadership ability", "IA" is "innovation ability", "CSE" is "collage students' entrepreneurship”. Similarly hereinafter.

\section{3) The analysis of multivariate regression of CSDSB and CSE}

Taking the scores of CSDSB and its six factors as independent variables, and the scores of CSE as dependent variable, stepwise regression analysis has been carried out. The results are shown in Table 4. It is shown in Table 4 that the variance test of regression equation is significant $(\mathrm{F}=32.375, \mathrm{P}=0.000)$, which indicates that the regression model between the total average score of CSDSB and one of its six factor and CSE fits very well. There are two significant variables among 7 predictors of CSDSBS into the regression equation. The multivariate correlation coefficient is 0.831 , and the joint interpretation variance is 0.691 , which is that the two variables in the table can predict $69.1 \%$ of the variance of CSE. Among these two variables, the most influential one is the total average score of CSDSB, which indicates that CSDSB has a significant positive predictive effect on CSE. 
Table 4. The analysis of multivariate regression of CSDSB and CSE

\begin{tabular}{ccccccccc}
\hline DV & PV & $\mathrm{R}$ & $\mathrm{R}^{2}$ & $\mathrm{aR}^{2}$ & $\mathrm{~F}$ & $\mathrm{~B}$ & Beta & $\mathrm{t}$ \\
\hline \multirow{3}{*}{$\mathrm{CSE}$} & $\mathrm{EM}$ & 0.831 & 0.691 & 0.669 & $32.375^{* * *}$ & 0.154 & & 0.304 \\
& $\mathrm{CSDSB}$ & & & & & 0.553 & 0.436 & $2.380^{*}$ \\
& $\mathrm{Ex}$ & & & & & 0.424 & 0.434 & $2.366^{*}$ \\
\hline
\end{tabular}

Noting: "DV" is "dependent variable", "PV" is "predictive variable" or "predictor" or

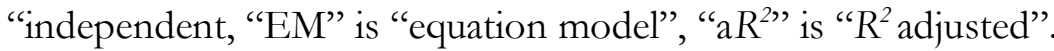

\section{b. Interview Results and Analysis}

There are 4 interviewees who graduated from 2 universities and 1 collage in Guangdong Province, with 3 undergraduate graduates and 1 college graduate. Each of them has set up automobile service company, law firm, cultural communication company and ecommerce respectively.

Table 5. The information of interviewees

\begin{tabular}{|c|c|c|c|c|}
\hline Name & Entrepreneurial projects & Grade & Major & Graduated from \\
\hline Interviewee 1 & $\begin{array}{l}\text { Huaying Cultural } \\
\text { Communication Co., Ltd. }\end{array}$ & 2012 & $\begin{array}{l}\text { Tourism } \\
\text { Management }\end{array}$ & $\begin{array}{l}\text { Zhaoqing } \\
\text { University }\end{array}$ \\
\hline Interviewee 2 & Xinyue e-commerce & 2015 & $\begin{array}{l}\text { Business } \\
\text { Management }\end{array}$ & $\begin{array}{l}\text { Panyu } \\
\text { Polytechnic }\end{array}$ \\
\hline Interviewee 3 & Jingfang law firm & 2004 & Law & $\begin{array}{l}\text { Shaoguan } \\
\text { University }\end{array}$ \\
\hline Interviewee 4 & $\begin{array}{l}\text { Jiwying Automobile } \\
\text { Service Co., Ltd. }\end{array}$ & 2008 & $\begin{array}{l}\text { Human } \\
\text { resource } \\
\text { Management }\end{array}$ & $\begin{array}{l}\text { Zhaoqing } \\
\text { University }\end{array}$ \\
\hline
\end{tabular}

\section{1) Definition and Understanding of Entrepreneurship}

In order to gain a deeper understanding of interviewees' definition and understanding of entrepreneurship, there are two questions set up that are related to the definition and understanding of entrepreneurship. One is the first that is about the definition of entrepreneurship, the other is the fourth that is about the overall summary of entrepreneurship experience.

In the questioning of the definition of entrepreneurship, all of four interviewees mentioned "innovative consciousness", including innovative consciousness, innovative spirit and looking for new ways; three of them mentioned "persistence" that is their desire for success and persistence; three of them mentioned "ability", including execution, economic ability and insight; two of them mentioned "team", that is, a group of likeminded people do the same thing for a vision and goal; to refer to "profitability" as creating performance and making profits, which is consistent with the definition of entrepreneurship. Regarding the feelings and experiences in the process of entrepreneurship, four interviewees mentioned different understandings and feelings of "pressure", "perseverance", "effort", "diligence", "growth", "hardship", "judgment and insight on business opportunities". Despite so, the overall view is consistent with the above definition of entrepreneurship. Individual entrepreneurship and entrepreneurial environment affect their respective entrepreneurs' feelings in the process of entrepreneurship, but overall, every interviewee is experiencing opportunities and challenges, both coexist. 


\section{2) Opportunities for Entrepreneurship}

In order to understand the entrepreneurship ideas and reasons of the interviewees, two questions were designed in the interview. One is the second question that is "When did you start to have the entrepreneurial idea? Did what prompt you to have the idea?" The other is the third question that is "When did you start your business? What was the reason why you chose to start your business?" As for the second question, 3 interviewees had the idea of starting a business before they went into university or college, one had after employment. Two of them are for economic independence and to reduce family burdens; one is achieving the desired results by entrepreneurship when he encountered professional bottlenecks and needed more resources integration; and one believed that only by constantly innovating and making progress can he keep pace with the changes of the times. For the third question, four interviewees all mentioned the realization of personal value. Two of them believed that the reasons that people survive in this society are the promotion of self-worth, set-up of brands and building of team rather than money. One of them believed that he had caught up with the trend of "mass entrepreneurship, mass innovation" that provided opportunities for entrepreneurship. It can be seen that with the development of the times, students easily access relevant innovative information so that their entrepreneurial ideas sprout earlier. Entrepreneurship may be a viable choice for those who are already stunk in the workplace. Contemporary college students just catch up with the good time that the State advocates innovation and entrepreneurship, which the state has policy support, and colleges and universities have positive measures that foster and promote students' entrepreneurial literacy. In order to cultivate and improve students' entrepreneurship, colleges and universities actively respond to the call of the state to provide opportunities for students to observe the social industry situation, participate in practice, and let students get exercise in society.

\section{3) Entrepreneurial Behavior Quality}

In order to clarify the entrepreneurship quality of the respondents, three questions are designed to ask interviewees in this survey, which are respectively the fifth question that is "What do you pay most attention to during the entrepreneurship period?", the sixth question that is "What do you think are your most valuable qualities in the process of starting a business?", the seventh question that is "What qualities do you think college students need to have in their entrepreneurship?"

In the answer to the fifth question, the four respondents mentioned personal qualities, most of which were "personal abilities" (4 times), followed by "teamwork" (3 times), "integrity" (2 times), "social etiquette"( 1 times) and "confidence" (1 times). In the answer to the sixth question, the interviewees mentioned "curiosity" and "pushfulness" In addition to the qualities above. In answer to the seventh question, all interviewees believed that college students should have "good psychological quality", "self-confidence", "execution", "integrity", "innovation spirit", etc. From the answers to the questions of the above interviewees, although they attach different importance to various daily behavior, the entrepreneurial qualities mentioned by them are all included in the CSDBS, which fully illustrates the importance of College Students' good daily behavior to their successful entrepreneurship. Generally speaking, college students' behavior habits will not only have an important impact on their interpersonal communication, learning and work, but also affect the personal abilities that are needed on their way of entrepreneurship. 


\section{4) Cultivation of entrepreneurial behavior quality}

On how to cultivate innovation and entrepreneurship of college students, four interviewees mentioned respectively to cultivate their good mentality, ability to handle trouble, ability of team cooperation, desire for knowledge, self-judgment ability, ability of interpersonal communication and innovation consciousness, to let them contact the society more in order to understand the development of the industry, to train their practical ability, to improve their personal psychological quality and risk awareness, etc. The interviewees' answers are mainly for the school. Colleges and universities should cultivate students' entrepreneurial quality according to the requirements of entrepreneurship. Of course, because personal characteristics, family environment and social and cultural conditions, etc. play an irreplaceable role in the cultivation of students' entrepreneurial quality, we should make full use of various factors to cultivate students' entrepreneurial quality.

\subsection{Discussion}

\section{1) The analysis in descriptive statistical results of CSDSB}

The descriptive statistical results of CSDSB show that among the six dimensions of the scale, Dream scores the highest and Creativity scores the lowest. The low level of creativity of contemporary college students can be attributed to contemporary educational problems. Contemporary college students have received exam-oriented education since their childhood, as the result that they lack the ability of independent thinking and criticalness, and their development of creativity is limited. Generally speaking, their teachers and parents tend to focus on their children's test results, but easily to ignore the cultivation of imagination and creativity (Cao, Liu, 2019). The above analyses show that college students should not only be interested in and pursue life goals, seize opportunities and keep pace with the times, but also cultivate their own creative thinking, which is very important to improve their daily successful behavior quality.

\section{2) The Analysis of Gender Difference in CSDSB}

The results show that there are significant differences in the score of creativity between male and female students that the male is higher than that of the female, which is similar to the research results of Zhu Haixue and Song Deru (2016), which reasons are that their subjects of study are local college students. The reason why men are more creative than women is related to the traditional gender education in China that parents and teachers place on different expectations and requirements in the cultivation of children according to gender differences. Chinese traditional culture, especially the leading ideology of Confucianism, emphasizes that men shoulder the responsibility of uniting the family, governing the country and making the world peaceful. Therefore, men are expected to have high demands on themselves, stronger risk-taking ability and higher control ability, which would lead to male students attaching more importance to innovation and entrepreneurship and working harder.

\section{3) Correlation Analysis of CSDSB and Entrepreneurship}

Through the study, it is found that the total score of CSDSB and its dimensions of creativity, excellence, dreams, physical and mental health, integrity is significantly positively correlated with entrepreneurship, which is similar to Qi Runsheng's research. The reason for this result is that CSDSB and its various dimensions may be the behavioral characteristics needed for entrepreneurship. From the analysis of college students' entrepreneurship, if they want to succeed in entrepreneurship, they should have the psychological and behavioral qualities of creativity, excelsior, dream, physical and mental health, integrity and so on. For example, without creativity, no new question would be proposed, and no new method found, 
and no new ideas constructed; without excelsior, people would not try their best to achieve the ultimate cause; without dreams, there would a lack of the desire and the pursuit of a good life in the future, and there would be a lack of power to struggle; which all would lead to the failure of the start-up.

\section{4) Regression Analysis of CSDSB and CSE}

The results show that the total score of CSDSB and the dimension of excellence enter the regression equation, which can effectively explain $69.1 \%$ of the variance and have a positive predictive effect on CSE, which can be explained as the standardization and cultivation of positive behavior quality of college students would help to improve their chances of successful entrepreneurship. Some researchers believe that with the advent of the era of higher education popularization, colleges and universities gradually expand enrollment, and the overall quality of college students exists a downward trend. In recent years, there are endless reports about the anomie of college students' daily behavior. It is believed that most of the contemporary college students have daily behavior problems (Wang, Deng, Zeng, 2016), which is extremely unfavorable to the cultivation of College Students' entrepreneurship. In the process of popularization of education, if the quality of education is not taken into account, the overflow of behavioral anomie would be resulted. College students are entrepreneurial group with great potential for development, their good entrepreneurial quality is a very favorable condition for them to succeed in starting a business. Since CSDSB is closely related to CSE, in order to enable college students to have good entrepreneurial quality, it is necessary to try to intervene in their daily behavior, and cultivate their good behavior habits, so that they can keep up with the pace of the times, conform to the trend of social development, and successful entrepreneurs.

\section{Conclusion}

There are significant gender differences in the creativity of CSDSB. The total score of CSDSB and the scores of its dimensions of dreams, creativity, physical and mental health, integrity, excelsior is significantly correlated with the scores of CSE and its four dimensions. The total score of CSDSB and the score of its dimension of excelsior are able to significantly predict CSE. The daily behavioral factors of the interviewees have a positive impact on their successful entrepreneur.

\section{References}

Amal, B. K., Natsir, M., Supsiloani, Suswati, R. (2019). Mixed Method Strategies to Develop The Acquisition of ESP Students' Skills of on Line Marketing. Budapest International Research and Critics in Linguistics and Education (BirLE) Journal, 2(1), 72-78.

Cao, X.-d., Liu, W.(2019). On the Cultivation of Undergraduates' Creative Thinking Ability under the Innovative Talent Training Mode_-Taking the Course of An Introduction to Geoscience as an Example. Journal of Zunyi Normal University, 21(1), 129-132.

Gartner, W. B.(1990). What are we talking about when we talk about entrepreneurship?[J]. Social Science Electronic Publishing, 5(1):15-28.

Gu, L.-q.(2013). On the Cultivation of College Students' Entrepreneurship. (Doctor), Liaoning University, Shenyang, China.

Huang, Z.-w. (2018). On cultivating innovation and entrepreneurship talents for foreign language majors from the perspective of entrepreneurship experience interview. Technology and Economic Guide, 26(27), 144-145. 
Li, X. (2010). A Study on the Cultivation Education of College Students'Behavior Habits. (Master), East China Normal University, Shanghai.

Liu R.-q.(2017). The Study on the Cultivation of University Students' Behavioral Habits under the View of Positive Psychology. (Master), Xi'an Technological University, Xi'an, China.

Rosmadi, L. M. N. (2018). Factors in Developing Creative Industry. Budapest International Research and Critics Institute (BIRCI-Journal) : Humanities and Social Sciences, 1(4), 64-69.

Wang X.-b.(2019). On the valuable Influence of the Long March Spirit on College students' Education about Ideal and Belief. Journal of Zunyi Normal University, 21(1), 5-9.

Wang, Y.-m. (2014). Study on the Effect of Family Environment on University Entrepreneurship. (Master), Jiangxi Normal University, Nanchang.

Wang, Y.-q., Deng, Y-y., Zeng, L.-p.(2018). A Summary of the Research on the Management Strategies of Students'Daily Behavior at All Levels. Ability and Wisdom. (17),34$35+37$.

Zhang, Y., Shang, Zh.-r., Hu, R., etc.. (2019). The Compilation of daily life behavior scale for college students. China Journal of Health Psychology, 27(8), 1247-1252.

Zhu, H.-x., Song, D.-r.(2016). Research on the relationship between cognitive style and creative tendency of college students. Journal of Chifeng University(Natural Science Edition). 32(24), 69-70. 